\title{
Letter to the editor: Use of radioactive iodine treatment in patients with hyperthyroidism? A case for shared decision making
}

\author{
Tristan Struja $^{1,2}$ (D) $\cdot$ Philipp Schuetz ${ }^{1,3}$
}

Received: 17 July 2019 / Accepted: 29 July 2019 / Published online: 3 August 2019

(C) Springer-Verlag GmbH Germany, part of Springer Nature 2019

\section{Dear Editor,}

The analysis published by Kithara and colleagues regarding the association of radio-iodine exposure and later risk of cancer is of great importance and should impact the way we use this treatment in patients with hyperthyroidism [1]. Their cohort consisted of 18,805 patients with a mean age of 49 years at entry. The majority of patients included in the analysis (94\%) received radio-iodine for Graves' disease. Authors calculated a lifetime excess of solid cancer deaths of 12 (95\% confidence interval 2-26) to 31 (95\% confidence interval 5-64) per 1000 patients treated at age of 50, respectively. Graves' disease is a condition that can also be treated by antithyroid drugs. However, this therapy has a relapse rate of around 30-60\% depending on individual patients' factors [2].

The 2016 American Thyroid Association guidelines for diagnosis and management of hyperthyroidism recommend that patients with overt Graves' hyperthyroidism should be treated with any of the following modalities including radioiodine, antithyroid drugs, or surgery [2]. These guidelines also state that there is not enough evidence to assume a relevant cancer risk after radioactive iodine treatment [2], a statement that now needs revision given the new evidence presented [1]. When counseling patients regarding the best first-line

This article is part of the Topical Collection on Endocrinology

Tristan Struja

tristan.struja@gmail.com

Philipp Schuetz

schuetzph@gmail.com

1 University Clinic of Medicine, Kantonsspital Aarau, Aarau, Switzerland

2 University Clinic of Medicine, Division of Endocrinology, Diabetes, and Metabolism, Kantonsspital Aarau, Aarau, Switzerland

3 Medical Faculty, University of Basel, Basel, Switzerland treatment for Graves' disease, physicians should use a shared decision making approach outlining the risks and benefits of each treatment option and providing estimates regarding recurrence risks with antithyroid drug therapy based on recently published clinical scores (i.e., GREAT score) [3, 4].

\section{Compliance with ethical standards}

Conflict of interest The authors declare that they have no conflict of interest.

Ethical approval This article does not contain any studies with human participants performed by any of the authors.

\section{References}

1. Kitahara CM, Berrington de Gonzalez A, Bouville A, et al. Association of radioactive iodine treatment with cancer mortality in patients with hyperthyroidism. JAMA Intern Med. https://oi.org/ 10.1001/jamainternmed.2019.0981

2. Ross DS, Burch HB, Cooper DS, Greenlee MC, Laurberg P, Maia AL, et al. 2016 American Thyroid Association guidelines for diagnosis and management of hyperthyroidism and other causes of thyrotoxicosis. Thyroid. 2016;26(10):1343-421.

3. Struja T, Kaeslin M, Boesiger F, Jutzi R, Imahorn N, Kutz A, et al. External validation of the GREAT score to predict relapse risk in Graves' disease: results from a multicenter, retrospective study with 741 patients. Eur J Endocrinol. 2017;176(4):413-9.

4. Vos XG, Endert E, Zwinderman AH, Tijssen JG, Wiersinga WM. Predicting the risk of recurrence before the start of antithyroid drug therapy in patients with Graves' hyperthyroidism. J Clin Endocrinol Metab. 2016;101(4):1381-9.

Publisher's note Springer Nature remains neutral with regard to jurisdictional claims in published maps and institutional affiliations. 